\title{
Increased urinary podocytes following indomethacin suggests drug-induced glomerular injury
}

\author{
Alison L. Kent • Linda Brown • Margaret Broom • \\ Amy Broomfield • Jane E. Dahlstrom
}

Received: 5 October 2011 /Revised: 5 January 2012 / Accepted: 6 January 2012 /Published online: 14 March 2012

(C) IPNA 2012

\begin{abstract}
Background Preterm infants are delivered while glomerulogenesis is ongoing and may be exposed to insults, including medications that may affect renal development. Podocytes detected in the urine are an indicator of glomerular injury. The aims of this study were to determine whether preterm and term infants excrete podocytes in their urine and whether exposure to gentamicin and indomethacin increase podocyte excretion in their urine.

Methods Preterm infants $<33$ weeks gestation had urine collected each day while receiving either gentamicin or indomethacin. Preterm and term control infants had urine collected for 3 days. The number of casts and podocytes present in the urine of infants receiving indomethacin and gentamicin were compared with preterm and term control infants.

Results Forty-two neonates were included in the study. Podocytes were present in small numbers $(<2)$ in the urine of both preterm and term control neonates. The number of podocytes in the preterm group receiving indomethacin was significantly higher than in all other groups $(p=0.02)$, as was urinary albumin $(p=0.02)$.

Conclusions Increased number of podocytes in preterm neonates receiving indomethacin and higher excretion of
\end{abstract}

A. L. Kent $(\bowtie) \cdot$ M. Broom

Department of Neonatology, Canberra Hospital,

PO Box 11, Woden 2606, ACT, Australia

e-mail: alison.kent@act.gov.au

\author{
A. L. Kent $\cdot$ J. E. Dahlstrom \\ Australian National University Medical School, \\ Canberra, ACT, Australia \\ L. Brown · A. Broomfield · J. E. Dahlstrom \\ Department of Anatomical Pathology, Canberra Hospital, \\ PO Box 11, Woden 2606, ACT, Australia
}

albumin suggest glomerular injury is occurring. It is unknown whether injury to glomeruli during glomerulogenesis in preterm neonates has long-term sequelae for renal development and function into adulthood.

Keywords Podocyte · Preterm - Neonate - Gentamicin . Indomethacin $\cdot$ Cytology $\cdot$ Kidney $\cdot$ Urine

\section{Introduction}

Premature birth ( $<37$ weeks gestation) occurs in up to $12 \%$ of deliveries and occurs in 1-3\% of pregnancies $<29$ weeks gestation [1]. In the human, glomerulogenesis continues until 36 weeks gestation. The metanephron develops at 5 weeks gestation, with vesicular glomeruli development occurring at 18 weeks gestation. Glomerular tubular development occurs from 24 weeks gestation and is finally complete at 36 weeks gestation [2-4]. A number of potential renal insults may occur following preterm delivery. Patent ductus arteriosus (PDA) occurs commonly in the premature neonate, and indomethacin is frequently used to close the ductus. Indomethacin is known to be nephrotoxic, causing acute kidney injury in up to $25 \%$ of neonates [5]. Gentamicin is frequently administered to the premature neonate, often at the same time as indomethacin. Gentamicin is also known to be nephrotoxic and has been shown in in vitro studies to affect nephron development [6]. The effect of these nephrotoxic drugs in the human neonate during glomerulogenesis is unknown. Reduction in the number of glomeruli has been implicated in the development of hypertension and subsequent cardiovascular disease in animal models and human studies [7-11]. In a neonatal rat model, electron microscopic evidence of significant glomerular injury with foot process effacement of the glomerular 
Table 1 Demographics of neonates

\begin{tabular}{lllll}
\hline & Preterm control $(n=7)$ & Term control $(n=12$ & Preterm gentamicin $(n=13)$ & Preterm indomethacin $(n=10)$ \\
\hline Mean gestation weeks $( \pm \mathrm{SD})$ & $30.7(0.96)$ & $37.1(1.5)$ & $30.1(1.6)$ & $26.4(1.7)$ \\
Mean BWt grams $( \pm \mathrm{SD})$ & $1,483(391)$ & $3,164(769)$ & $1,467(290)$ & $944(897)$ \\
Mean maternal age $\pm(\mathrm{SD})$ & $30(4.6)$ & $27.7(3.4)$ & $30.4(4.9)$ & $29.7(5.2)$ \\
Mean Apgar 1 $( \pm \mathrm{SD})$ & $5.3(1.5)$ & $7.6(1.4)$ & $6.5(1.7)$ & $4.3(1.3)$ \\
Mean Apgar 5 $( \pm \mathrm{SD})$ & $7.0(2.0)$ & $8.3(1.1)$ & $7.9(1.1)$ & $6.3(1.1)$ \\
Maternal smoking & $0 / 7$ & $1 / 12$ & $5 / 13$ & $5 / 10$ \\
Male gender & $4 / 7$ & $8 / 12$ & $9 / 13$ & $5 / 10$ \\
Complete course antenatal steroids & $7 / 7$ & $0 / 12$ & $5 / 13$ & $2 / 10$ \\
Antenatal ampicillin & $0 / 7$ & $1 / 12$ & $8 / 13$ & $2 / 10$ \\
Antenatal gentamicin & $0 / 7$ & $0 / 12$ & $6 / 13$ & $6 / 10$ \\
Vaginal delivery & $0 / 7$ & $8 / 12$ & $7 / 13$ & \\
\hline
\end{tabular}

$B W t$ birthweight

basement membrane has been shown [12]. The podocyte is a highly differentiated cell that attaches to the outer aspect of the glomerular basement membrane. It has three main components: the cell body, major processes, and foot processes. The cell body and major process are not attached to the glomerular basement membrane but float in the Bowman's space. The foot processes that branch from the cell body and major processes attach to the basement membrane and interdigitate with the foot process of other podocytes [13]. The filtration slits that are formed between the interdigitations are bridged by an extracellular structure known as the slit diaphragm. The function of the podocyte foot processes, slit diaphragm, and glomerular basement membrane is to allow filtration of water and small solutes, but not larger molecules such as albumin. Damage to the podocyte has been implicated in the development of glomerulosclerosis, albuminuria, and the progression of renal diseases, including diabetic nephropathy [14-20]. Urinary excretion of podocytes has been shown in a number of renal conditions and may be a more specific marker of ongoing glomerular damage than is proteinuria [21-27]. Podocytes in the urine of preterm neonates could be a marker of glomerular injury as a result of potentially nephrotoxic insults. The aims of this study were to determine: (1) whether podocytes are excreted in the urine of preterm and term neonates and; (2) whether administration of indomethacin and gentamicin results in excretion of podocytes in the urine of preterm neonates.

\section{Methods}

After obtaining consent from a parent, neonates were divided into four groups and enrolled into the study: (1) neonates 24-32 weeks gestation receiving gentamicin (preterm gentamicin); (2) neonates 24-32 weeks gestation receiving indomethacin (preterm indomethacin); (3) neonates 24 32 weeks gestation not receiving gentamicin or indomethacin (preterm control); and (4) term neonates not receiving gentamicin or indomethacin and who were admitted for treatment of hyperbilirubinemia or hypoglycemia (term control). Infants with acute kidney injury, severe sepsis requiring inotropes or other nephrotoxic drugs, and with identified chromosomal or congenital anomalies were excluded. Data collected included gestational age, birth weight, exposure to antenatal steroids, maternal smoking, exposure to antenatal antibiotics, type of delivery, and Apgar scores.

Urine samples

Term and preterm control neonates not receiving gentamicin had three urine samples collected in the first 3-4 days of

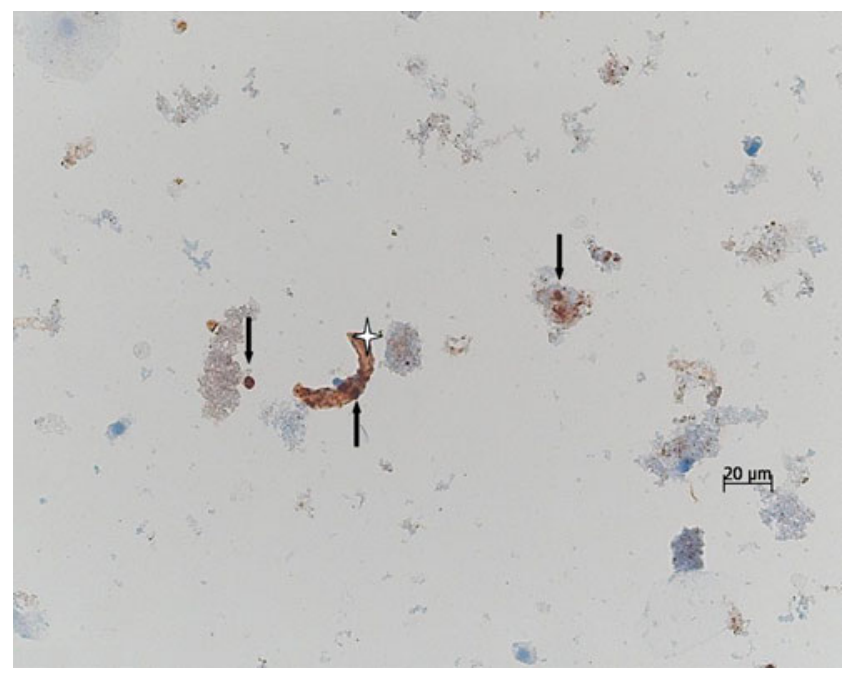

Fig. 1 Urine sample from a preterm male neonate from the indomethacin group showing multiple podocytes (arrows) and a single cast (asterisk), all expressing podocalyxin [single-staining phenazine methosulfate 5 (PMS5), original magnification $\mathrm{x} 400$ ) 
Table 2 Urinary podocyte, cast, and biochemistry results per group

\begin{tabular}{lllll}
\hline & $\begin{array}{l}\text { Preterm control } \\
(n=7)\end{array}$ & $\begin{array}{l}\text { Term control } \\
(n=12)\end{array}$ & $\begin{array}{l}\text { Preterm gentamicin } \\
(n=13)\end{array}$ & $\begin{array}{l}\text { Preterm indomethacin } \\
(n=10)\end{array}$ \\
\hline Median podocyte count $( \pm \mathrm{IQR})$ & $0.5(0-1.0)$ & $0.3(0-1.0)$ & $0.7(0.3-1.9)$ & $\begin{array}{l}2.4(1.6-6.4) \\
23.8(1.7-37.8)\end{array}$ \\
Median cast count $( \pm \mathrm{IQR})$ & $8.0(1.7-11.8)$ & $3.5(0.2-7.7)$ & $14.8(2.2-22.3)$ & 0.11 \\
Median urinary albumin $( \pm \mathrm{IQR})$ & $31(26-45.5)$ & $29.2(13.3-49.7)$ & $34.3(29.4-58)$ & $61(35.5-95.6)$ \\
Median urinary creatinine $( \pm \mathrm{IQR})$ & $1.4(1.1-1.7)$ & $1.3(1-1.7)$ & $1.0(0.7-1.6)$ & $\begin{array}{l}1.1(0.8-1.7) \\
49(46.3-73.9)\end{array}$ \\
Median urinary albumin:creatinine ratio $( \pm \mathrm{IQR})$ & $25.6(17.9-32)$ & $24.9(8.4-32.3)$ & $41.4(32-49.5)$ & 0.28 \\
\hline
\end{tabular}

$I Q R$ interquartile range

* $P<0.05$

admission to the neonatal intensive care unit. Urine was collected using plastic wrap placed in the nappy of female neonates and aspirated using a syringe. Male infants had a urine collection bag placed over the penis and urine aspirated by syringe from the collection bag. Preterm neonates receiving gentamicin and preterm neonates receiving indomethacin had urine samples collected on each day they were receiving treatment and 1 week following treatment. Samples were collected for urine albumin, urine creatinine, and albumin:creatinine ratio, as well as for cytological examination for podocyte and cast assessment.

\section{Cytological assessment}

Samples were prepared as soon as practicable on receipt in the laboratory, generally within $1 \mathrm{~h}$ of collection (even outside normal working hours). Three slides were prepared for each sample received. As some samples were extremely low in volume, $1.0 \mathrm{ml}$ of CytoLyt was added to all samples and the sample was then divided into three single-hole chambers of the centrifuge, using a maximum of $0.5 \mathrm{ml}$ of urine for each slide. Cytospins were prepared by centrifugation at $600 \mathrm{rpm}$ for $5 \mathrm{~min}$. Two slides were air dried on positively charged slides and a third slide was fixed in $95 \%$ alcohol for $20 \mathrm{~min}$. The alcohol-fixed slide was stained with (PAP). The air-dried slides were fixed in 100\% alcohol for $10 \mathrm{~min}$ then rehydrated prior to immunohistochemistry on the BenchMarch immunohistochemical (IHC) staining module (Ventana). Both single [diaminobenzidine (DAB)] and double (DAB and Red Naphthol) staining was performed. The slides were incubated with monoclonal antibody markers for podocytes (antihuman podocalyxin, PHM5, Millipore 1/40 dilution with no retrieval, Chemicon, Boronia, VIC, Australia) and a macrophage marker (CD68, DakoCytomation, 1/1500 dilution with standard heat retrieval for $32 \mathrm{~min}$ ). Nucleated podocalyxin-positive cells were considered to be podocytes. Light microscopy and immunohistochemistry was assessed by one cytologist blinded to the treatment group. Each urine sample was assessed for the following features: presence and number of podocytes, presence and number of macrophages, presence and number of casts, presence of inflammatory cells, presence of squamous cells and urothelial cells, and presence of bacteria. The immunohistochemistry was used to aid in identification of the podocytes and to distinguish them from macrophages; $30 \%$ of the slides were independently assessed by a pathologist, and a consensus was reached regarding numbers of podocytes present in each slide if there was a difference.

\section{Statistical analysis}

Statistical analyzes were performed using the Predictive Analytics Software (PASW for windows. Release 18.02 SPSS: An IBM Company, Chicago, IL, USA). Numerical values were analyzed using Kruskal-Wallis nonparametric
Fig. 2 Urinary podocyte, cast, and biochemistry results $\left({ }^{*} p<\right.$ 0.05 ,as per Table 2)

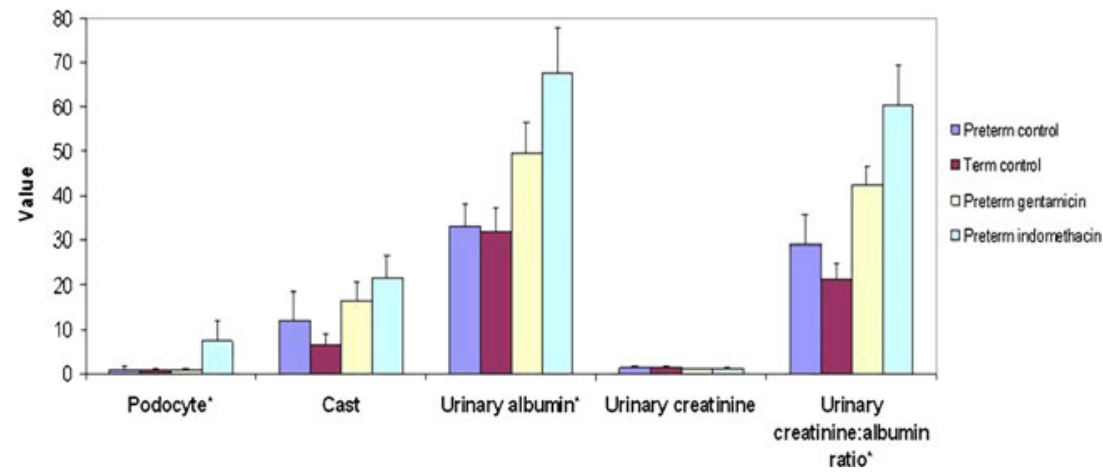




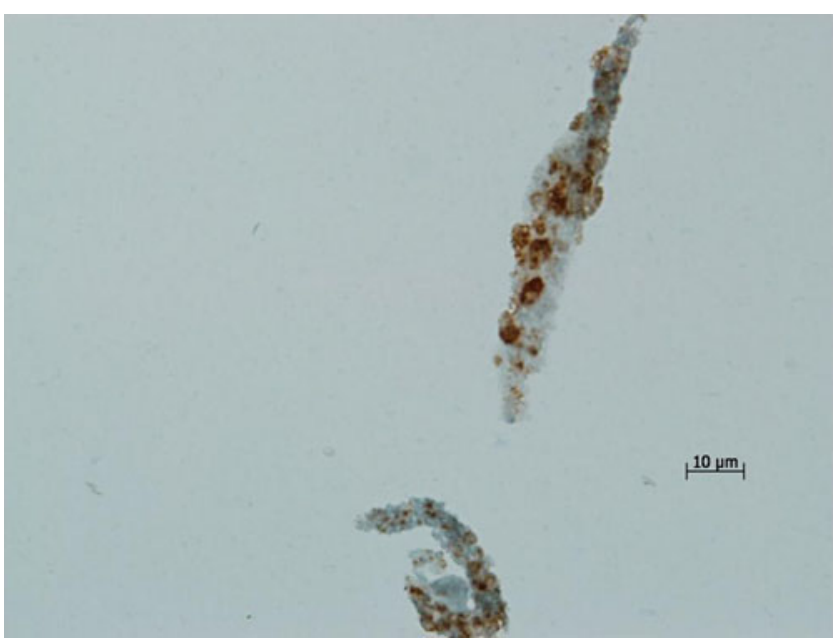

Fig. 3 Urine sample from a preterm male neonate from the indomethacin group showing granular casts staining brown with podocalyxin [single-staining phenazine methosulfate 5 (PMS5), original magnification $\mathrm{x} 1,000]$

tests for nonnormally distributed data. Categorical values were analyzed using the chi-square test. A $p$ value of $<0.05$ was considered significant. For analysis, the average number of podocytes, casts, urinary albumin, urinary creatinine, and urinary albumin:creatinine ratio per number of urine samples submitted during treatment was used. The study was approved by the local Human Research Ethics Committee.

\section{Results}

Forty-two infants were enrolled into the study; the demographics of infants in each group are provided in Table 1 . Between the preterm groups, the indomethacin group was of younger gestation $(p<0.0001)$, birthweight $(p=0.001)$, and had lower Apgar scores ( $p=0.006$ and 0.04 , respectively), which is to be expected, as this is the group with the highest risk of requiring treatment for a PDA. The preterm control group were more likely to have received a complete course of antenatal steroids $(p=0.03)$ and less likely to have received antenatal ampicillin $(p=0.01)$, as they were electively delivered for maternal hypertension. The differences between the term control groups and the preterm groups were to be expected due to gestational age, birthweight, exposure to antenatal steroids, and antenatal antibiotics. There were no significant differences between maternal age and maternal smoking between groups.

Podocytes and casts were found in the urine of all groups of neonates; however, in preterm and term control groups, only one infant on average had more than one podocyte in their urine. The number of podocytes in the preterm group receiving indomethacin was significantly higher than all other groups $(p=0.02)$ (Fig. 1), as was urinary albumin $(p=0.02)$. Urinary albumin:creatinine ratio was significantly higher in the preterm group receiving indomethacin $(p<$ 0.0001) (Table 2 and Fig. 2). Mean patient age of administration of indomethacin was 6.6 (range 2-18) days, indicating that the elevated ratio was related to medication administration rather than postnatal age. The number of casts in the indomethacin-treated group was greater than in the other groups but did not reach statistical significance (Fig. 3). There were no significant differences in the number of podocytes or casts during treatment and 1 week following treatment in either the preterm gentamicin $(p=0.44 ; p=0.14$, respectively) or preterm indomethacin ( $p=0.26 ; p=0.77$, respectively) groups, although these groups had more inflammatory cells and background amorphous debris than the control groups (Fig. 4a, b). There was no significant

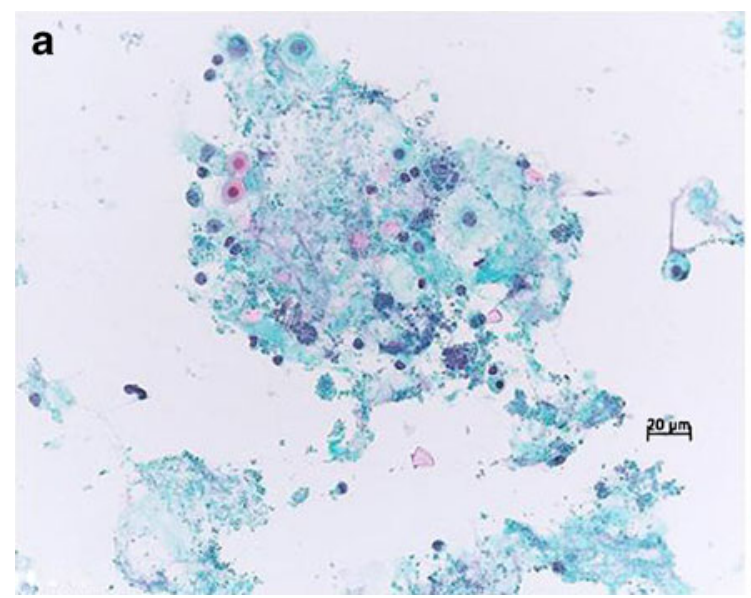

Fig. 4 a Urine sample from a preterm male infant receiving gentamicin showing large numbers of micro-orgamisms, red blood cells, and macrophages [Papanicolaou (PAP) stain, original magnification $\mathrm{x} 400$ ]. b Urine sample from the same preterm male infant receiving

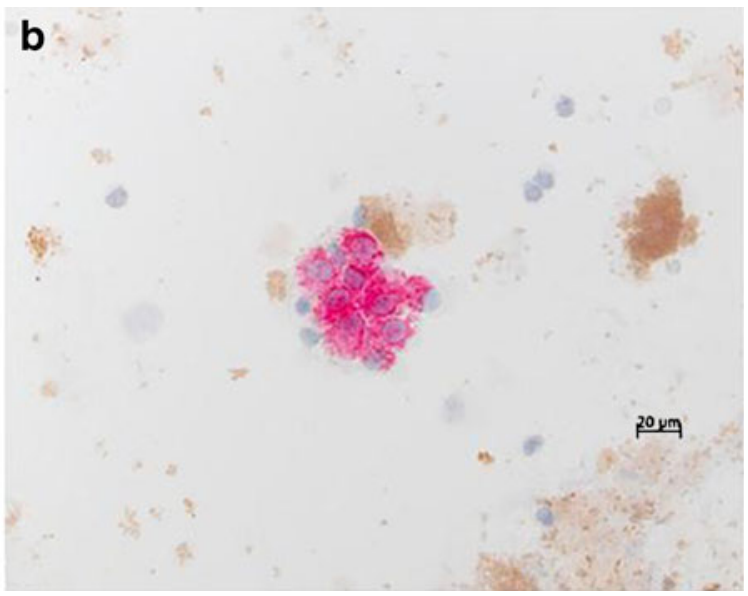

gentamicin showing a cluster of macrophages (stained red) in a background showing amorphous debris that is highlighted with the podocyte marker phenazine methosulfate (PMS) (stained brown) (double staining CD68 and PMS5, original magnification $\mathrm{x} 400$ ) 
Table 3 Urinary podocyte, cast, and biochemistry results between preterm and term infants

\begin{tabular}{|c|c|c|c|c|c|}
\hline & $\begin{array}{l}\text { Term control } \\
(n=12)\end{array}$ & Preterm $(n=30)$ & $P$ value & $\begin{array}{l}\text { Preterm excluding } \\
\text { indomethacin }(n=20)\end{array}$ & $P$ value \\
\hline Median podocyte count $( \pm \mathrm{IQR})$ & $0.3(0-1.0)$ & $1.0(0.3-2.3)$ & $0.04 *$ & $0.6(0.3-1.7)$ & 0.22 \\
\hline Median cast count $( \pm \mathrm{IQR})$ & $3.5(0.2-7.7)$ & $13.5(1.8-25.1)$ & $0.03 *$ & $10.9(2-19.8)$ & 0.08 \\
\hline Median urinary albumin $( \pm \mathrm{IQR})$ & $29.2(13.3-49.7)$ & $37.1(29.5-60.6)$ & 0.05 & $32.3(28.6-53.5)$ & 0.24 \\
\hline Median urinary creatinine $( \pm \mathrm{IQR})$ & $1.3(1-1.7)$ & $1.1(0.8-1.6)$ & 0.23 & $1.2(0.8-1.7)$ & 0.32 \\
\hline Median urinary albumin:creatinine ratio $( \pm \mathrm{IQR})$ & $24.9(8.4-32.3)$ & $43.5(28.5-53.7)$ & $0.001 *$ & $33.5(26.3-47.5)$ & $0.009^{*}$ \\
\hline
\end{tabular}

$I Q R$ interquartile ratio

$* P<0.05$

difference in creatinine levels on the first day of treatment between groups, the medians being $72 \mu \mathrm{mol} / \mathrm{L}, 63 \mu \mathrm{mol} / \mathrm{L}$, $60 \mu \mathrm{mol} / \mathrm{L}$, and $63 \mu \mathrm{mol} / \mathrm{L}$, respectively $(p=0.7)$.

An analysis was performed comparing all preterm groups with term neonates. Preterm neonates had a significantly higher number of podocytes and casts in their urine in comparison with term neonates ( $p=0.04 ; p=0.03$, respectively). Urinary albumin was higher in preterm neonates but did not reach statistical significance, and there was no difference between urinary creatinine between preterm and term neonates $(p=0.05 ; p=0.23)$ ( Table 3$)$. With removal of the indomethacin-treated preterm group, this difference was no longer evident $(p=0.22)$. As expected, urine from female infants had more squames than that of male infants (Fig. 5).

\section{Discussion}

This study is the first reported in the literature to look for podocytes in the urine of neonates, and both podocytes and

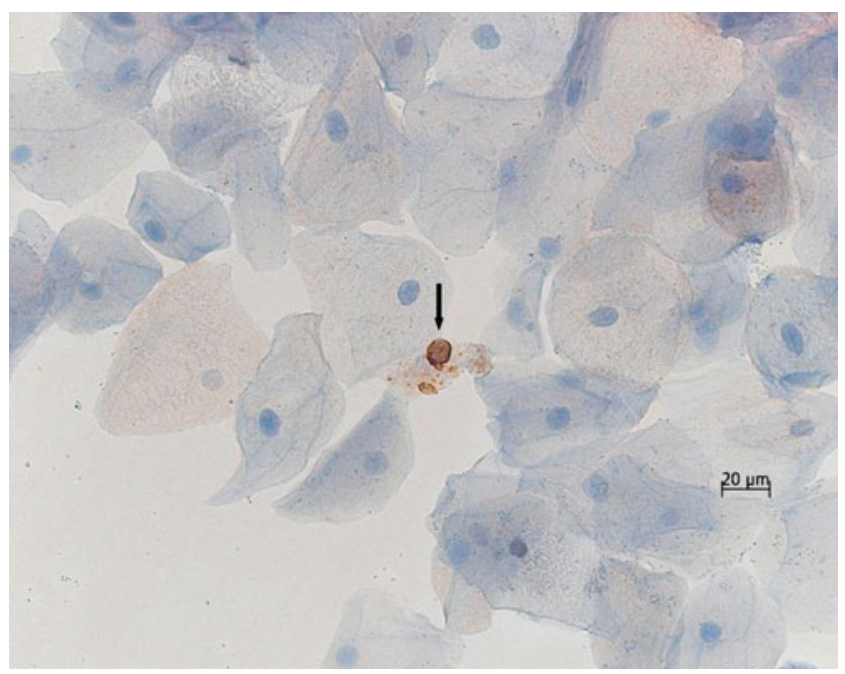

Fig. 5 Photomicrograph of a urine sample from a female neonate in the preterm control group showing a single podocyte (arrow) in a background of a large number of mature squames [single staining for phenazine methosulfate 5 (PMS5), original magnification $x 400$ ] casts were found in preterm and term neonates. This is also the first study reported in the literature to look for podocytes in the urine of neonates treated with gentamicin and indomethacin. Preterm neonates receiving indomethacin had significantly higher numbers of podocytes in their urine, suggesting that glomerular injury may be occurring in these infants. It is possible that because these infants were more preterm than the preterm control and gentamicin groups that this could account for the difference, but given that-across all gestational ages - there was generally only one podocyte in a urine sample, this would seem unlikely. Urinary albumin was also elevated in this group, which would go along with damage occurring at the podocyte level, damaging the slit diaphragm and allowing more albumin excretion to occur. The greater number of podocytes and casts in the urine of preterm neonates in comparison with term neonates was no longer significant after removal of the indomethacintreated group, although the trend was still toward a higher number. The preterm group receiving gentamicin did not have an increased number of podocytes in comparison with preterm control and term control groups, suggesting that gentamicin does not cause significant glomerular injury.

The presence of podocytes in the urine of preterm and term neonates has not been previously studied; thus, it was not possible to make a power calculation to determine the number of neonates needed in the study to determine a significant difference with treatment of gentamicin and indomethacin. Consequently, this is an initial study, and as such, the results may be affected by the small numbers of infants analyzed. Parietal podocytes and visceral podocytes stain with podocalyxin [28], and if parietal cells are present, this would also suggest glomerular injury. Urine samples were not collected at a specific time after drug administration due to the inherent difficulty of obtaining samples in extremely premature neonates and thus may affect the number of podocytes present in the urine. With some of the extremely premature neonates, an occasional urine sample was not always $0.5 \mathrm{ml}$ and was made up to $1 \mathrm{ml}$ with extra CytoLyt, which would have underestimated the number of podocytes. Given the small numbers of study participants, it 
is not possible to make a further analysis of other potential confounders, such as maternal smoking, antenatal steroid and antenatal gentamicin exposure.

Indomethacin has been shown to cause acute renal failure in up to $25 \%$ of neonates and from a neonatal animal model appears to involve glomerular as well as tubular injury [5, 12]. This study, which showed increased podocytes in the urine of neonates treated with indomethacin, supports this finding. We did not examine study participants for tubular cells in the urine to support our neonatal animal model, which showed both glomerular and tubular injury. Given these potential nephrotoxic insults, other possible treatment options might be considered for treatment of a PDA. However, the only other medical option for closure of the PDA is ibuprofen, which is also shown to injure glomeruli in a neonatal animal model and has been shown to affect glomerular filtration rate (GFR) during the first month of life in human studies $[12,29,30]$. Judicious use of these medications during the neonatal period is warranted and should be balanced with the clinical condition of the neonate and the severity of the PDA.

There is growing animal and human evidence that prematurity is associated with alterations in glomerulogenesis [31-35]. Although glomerulogenesis still occurs in preterm neonates, the morphology of these glomeruli is abnormal [36]. The reduction in glomerular number and abnormal morphology, and ultimately their function, may risk renal impairment later in life. Given these findings, it is preferable to avoid administration of drugs that may be nephrotoxic, particularly to the developing glomerulus, as this may have further impact on glomerular number and function later in life. The relationship between glomeruli number and hypertension in later life has been shown in human studies [37, 38]. There is emerging evidence that premature infants have higher blood pressure in young adulthood; the etiological cause of this is unclear [39-42].

Along with long-term follow-up of neurodevelopmental outcome, long-term renal follow-up of extremely premature neonates may be important as well. Rodriguez-Soriano et al. found that GFR and tubular phosphate transport was altered in school-age children born prematurely [43]. Early data on renal growth and volume of kidneys in those born preterm is unclear, with conflicting evidence [44, 45]. A study by Keijzer-Veen et al. found reduced renal length and volume in young adults 20 years after preterm birth [46]. More research is, however, required.

\section{Conclusions}

Preterm neonates receiving indomethacin have increased numbers of podocytes in their urine, suggesting that glomerular injury may be occurring. It is unknown whether injury to glomeruli during glomerulogenesis in preterm neonates has long-term sequelae for renal development and function into adulthood. Judicious use of indomethacin for treating PDA in extremely preterm neonates should be considered, weighing the short-term benefits with potential long-term sequelae.

Acknowledgements We acknowledge the support of Mr. Arin Chandra, who performed the immunohistochemistry for some patients, and the cytology staff, especially Darren Taylor, at the Canberra Hospital, for preparing the slides. This study was supported by a grant from the Private Practice Fund of the Canberra Hospital.

\section{References}

1. Newton ER (2005) Preterm labor, preterm premature rupture of membranes, and chorioamnionitis. Clin Perinatol 32:571-600

2. Naruse K, Fujieda M, Miyazaki E, Hayashi Y, Toi M, Fukui T, Kuroda N, Hiroi M, Kurashige T, Enzan H (2000) An immunohistochemical study of developing glomeruli in human fetal kidneys. Kidney Int 57:1836-1846

3. Horster MF, Braun GS, Huber SM (1999) Embryonic renal epithelia: Induction, nephrogenesis, and cell differentiation. Physiol Rev 79:1157-1191

4. Abrahamson DR (1991) Glomerulogenesis in the developing kidney. Semin Nephrol 11:375-389

5. Akima S, Kent A, Reynolds GJ, Gallagher M, Falk MC (2004) Indomethacin and renal impairment in neonates. Pediatr Nephrol 19:490-493

6. Gilbert T, Gaonach S, Moreau E, Merlet-Benichou C (1994) Defect of nephrogenesis induced by gentamicin in rat metanephric organ culture. Lab Invest 70:656-666

7. Black MJ, Wang Y, Bertram JF (2002) Nephron endowment and renal filtration surface area in young spontaneously hypertensive rats. Kidney Blood Press Res 25:20-26

8. Skov K, Nyengaard JR, Korsgaard N, Mulvany MK (1994) Number and size of renal glomeruli in spontaneously hypertensive rats. J Hypertension 12:1373-1376

9. Brenner BM, Chertow GM (1994) Congenital oligonephropathy and the etiology of adult hypertension and progressive renal injury. Am J Kidney Dis 23:171-175

10. Keller G, Zimmer G, Mall G, Ritz E, Amann K (2003) Nephron number in patients with primary hypertension. $\mathrm{N}$ Eng $\mathrm{J}$ Med 348:101-108

11. Zumrutdal AO, Turan C, Cetin F, Adanali S (2002) Relationship between renal size and hypertension in patients with chronic renal failure. Nephron 90:145-147

12. Kent AL, Maxwell LE, Koina ME, Falk MC, Willenborg D, Dahlstrom JE (2007) Renal glomeruli and tubular injury following indomethacin, ibuprofen and gentamicin exposure in a neonatal rat model. Pediatr Res 62:307-312

13. Mundel P, Kriz W (1995) Structure and function of podocytes: an update. Anat Embryol (Berl) 192:385-397

14. Kerjaschki D (2001) Caught flat-footed: Podocyte damage and the molecular bases of focal glomerulosclerosis. J Clin Invest 108:1583-1587

15. Pagtalunan ME, Miller PL, Jumping-Eagle S, Nelson RG, Myer BD, Rennke HG, Coplon NS, Sun L, Meyer TW (1997) Podocyte loss and progressive glomerular injury in Type II diabetes. J Clin Invest 99:342-348 
16. Nakamura T, Ushiyama C, Suzuki S, Hara M, Shimada N, Ebihara I, Koide H (2000) Urinary excretion of podocytes in patients with diabetic nephropathy. Nephrol Dial Transplant 15:1379-1383

17. Welsh GI, Coward RJ (2010) Podocytes, glucose and insulin. Curr Opin Nephrol Hypertens 19:379-384

18. Benoit G, Machuca E, Antignac C (2010) Hereditary nephrotic syndrome: a systematic approach for genetic testing and a review of associated podocyte gene mutations. Pediatr Nephrol 25:16211632

19. Mundel P, Reiser J (2010) Proteinuria: an enzymatic disease of the podocyte. Kidney Int 77:571-580

20. Stitt-Cavanagh E, MacLeod L, Kennedy C (2009) The podocyte in diabetic kidney disease. Sci World J 14:1127-1139

21. Vogelmann SU, Nelson WJ, Myers BD, Lemley KV (2003) Urinary excretion of viable podocytes in health and renal disease. Am J Physiol Renal Physiol 285:F40-F48

22. Hara M, Yanagihara T, Takada T, Itoh M, Matsuno M, Yamamoto T, Kihara I (1998) Urinary exretion of podocytes reflects disease activity in children with glomerulonephritis. Am J Nephrol 18:3541

23. Kanno K, Kawachi H, Uchida Y, Hara M, Shimizu F, Uchiyama M (2003) Urinary sediment podocalyxin in children with glomerular diseases. Nephron Clin Pract 95:c91-c99

24. Hara M, Yamamoto T, Yanagihara T, Takada T, Itoh M, Adachi Y, Yoshizumi A, Kawasaki K, Kihara I (1995) Urinary excretion of podocalyxin indicates glomerular epithelial cell injuries in glomerulonephritis. Nephron 69:397-403

25. Yu D, Petermann A, Kunter U, Rong S, Shankland SJ, Floege J (2005) Urinary podocyte loss is a more specific marker of ongoing glomerular damage than proteinuria. J Am Soc Nephrol 16:17331741

26. Hara M, Yanagihara T, Kihara I (2007) Cumulative excretion of urinary podocytes reflects disease progression in IgA nephropathy and Schönlein-Henoch purpura nephritis. Clin J Am Soc Nephrol 2:231-238

27. Petermann A, Floege J (2007) Podocyte damage resulting in podocyturia: a potential diagnostic marker to assess glomerular disease activity. Nephron Clin Pract 106:c61-c66

28. Bariety J, Mandet C, Hill GS, Bruneval P (2006) Parietal podocytes in normal human glomeruli. J Am Soc Nephrol 17:27702780

29. Vieux R, Fresson J, Guillemin F, Hascoet JM (2011) Perinatal drug exposure and renal function in very preterm infants. Arch Dis Child Fetal Neonatal Ed 96:F290-F295

30. Vieux R, Desandes R, Boubred F, Semana D, Guillemin F, Buchweiller M-C, Fresson J, Hascoet J-M (2010) Ibuprofen in very preterm infants impairs renal function for the first month of life. Pediatr Nephrol $25: 267-274$

31. Gubhaju L, Sutherland MR, Yoder BA, Zulli A, Bertram JF, Black MJ (2009) Is nephrogenesis affected by preterm birth? Studies in a non-human primate model. Am J Physiol Renal Physiol 297: F1668-F1677
32. Rodriguez MM, Gomez A, Abitbol C, Chandar J, Montane B, Zilleruelo G (2005) Comparative renal histomorphometry: a case study of oligonephropathy of prematurity. Pediatr Nephrol 20:945949

33. Rodriguez MM, Gomez AH, Abitbol CL, Chandar JJ, Duara S, Zilleruelo GE (2004) Histomorphometric analysis of postnatal glomerulogenesis in extremely preterm infants. Pediatr Dev Pathol 7:17-25

34. Manalich R, Reyes L, Herrera M, Melendi C, Rundora I (2000) Relationship between weight at birth and the number and size of renal glomeruli in humans: a histomorphometric study. Kidney Int 58:770-773

35. Faa G, Gerosa C, Fanni D, Nemolato S, Locci A, Cabras T, Marinelli V, Puddu M, Zaffanello M, Monga G, Fanos V (2010) Marked interindividual variability in renal maturation of preterm infants: lessons from autopsy. J Matern Fetal Neonatal Med 23 (Suppl 3):129-133

36. Sutherland MR, Gubhaju L, Moore L, Kent AL, Dahlstrom JE, Horne RS, Hoy W, Bertram JF, Black MJ (2011) Accelerated Maturation and Abnromal Morphology in the Preterm Neonatal Kidney. JASN 22:1365-1374

37. Brenner BM, Garcia DL, Anderson S (1988) Glomeruli and blood pressure. Less of one, more the other? Am J Hypertens 1:335-347

38. Hoy WE, Hughson MD, Singh GR, Douglas-Denton R, Bertram JF (2006) Reduced nephron number and glomerulomegaly in Australian Aborigines: A group at high risk for renal disease and hypertension. Kidney Int 70:104-110

39. Bonamy A-KE, Bendito A, Martin H, Andolf E, Sedin G, Norman M (2005) Preterm birth contributes to increased vascular resistance and higher blood pressure in adolescent girls. Pediatr Res 58:845849

40. Kistner A, Celsi G, Vanpee M, Jacobson SH (2005) Increased systolic daily ambulatory blood pressure in adult women born preterm. Pediatr Nephrol 20:232-233

41. Johansson S, Iliadou A, Bergvall N, Tuvemo T, Norman M, Cnattingius S (2005) Risk of high blood pressure among young men increases with degree of immaturity at birth. Circulation 112:3430-3436

42. Keijzer-Veen MG, Dulger A, Dekker FW, Nauta J, van der Heijden BJ (2010) Very preterm birth is a risk factor for increased systolic blood pressure at a young adult age. Pediatr Nephrol 25:509-516

43. Rodriguez-Soriano J, Aguirre M, Oliveros R, Vallo A (2005) Long-term renal follow-up of extremely low birth weight infants. Pediatr Nephrol 20:579-584

44. Huang H-P, Tsai I-J, Lai Y-C, Cheng C-H, Tsau Y-K (2007) Early postnatal renal growth in premature infants. Nephrol 12:572-575

45. Kent AL, Jyoti R, Robertson C, Gonsalves L, Meskell S, Shadbolt B, Falk MC (2009) Does extreme prematurity affect kidney volume at term corrected age? J Matern Fetal Neonatal Med 22:435-438

46. Keijzer-Veen MG, Devos AS, Meradji M, Dekker FW, Nauta J, van der Heijden BJ (2010) Reduced renal length and volume 20 years after very preterm birth. Pediatr Nephrol 25:499-507 